\title{
Regional modelling of tracer transport by tropical convection - Part 2: Sensitivity to model resolutions
}

\author{
J. Arteta ${ }^{1}$, V. Marécal ${ }^{1}$, and E. D. Rivière ${ }^{2}$ \\ ${ }^{1}$ Laboratoire de Physique et Chimie de l'Environnement et de l'Espace, CNRS and Université d'Orléans, 3A avenue de la \\ recherche scientifique, 45071 Orléans cedex 2, France \\ ${ }^{2}$ Groupe de Spectroscopie Moléculaire et Atmosphérique, Université de Reims Champagne-Ardenne and CNRS, Faculté des \\ sciences, Moulin de la Housse, B.P. 1039, 51687 Reims Cedex, France
}

Received: 29 December 2008 - Published in Atmos. Chem. Phys. Discuss.: 4 March 2009

Revised: 11 August 2009 - Accepted: 28 August 2009 - Published: 24 September 2009

\begin{abstract}
The general objective of this series of two papers is to evaluate long duration limited-area simulations with idealised tracers as a possible tool to assess the tracer transport in chemistry-transport models (CTMs). In this second paper we analyse the results of three simulations using different horizontal and vertical resolutions. The goal is to study the impact of the model spatial resolution on convective transport of idealized tracer in the tropics. The reference simulation (REF) uses a $60 \mathrm{~km}$ horizontal resolution and $300 \mathrm{~m}$ vertically in the upper troposphere/lower stratosphere (UTLS). A $20 \mathrm{~km}$ horizontal resolution simulation (HR) is run as well as a simulation with $850 \mathrm{~m}$ vertical resolution in the UTLS (CVR). The simulations are run for one month during the SCOUT-O3 field campaign. Aircraft data, TRMM rainrate estimates and radiosoundings have been used to evaluate the simulations. They show that the HR configuration gives generally a better agreement with the measurements than the REF simulation. The CVR simulation gives generally the worst results. The vertical distribution of the tropospheric tracers for the simulations has a similar shape with a $\sim 15 \mathrm{~km}$ altitude maximum for the $6 \mathrm{~h}$-lifetime tracer of $0.4 \mathrm{ppbv}$ for REF, 1.2 for HR and 0.04 for CVR. These differences are related to the dynamics produced by the three simulations that leads to larger values of the upward velocities on average for HR and lower for CVR compared to REF. HR simulates more frequent and stronger convection leading to enhanced fluxes compared to REF and higher detrainment levels compared to CVR. HR provides also occasional overshoots over the cold point dynamical barrier. For the stratospheric tracers the differences between the three simulations are small.
\end{abstract}

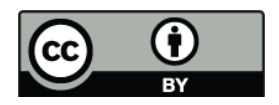

Correspondence to: J. Arteta (joaquim.arteta@cnrs-orleans.fr)
The diurnal cycle of the fluxes of all tracers in the Tropical Tropopause Layer exhibits a maximum linked to the maximum of convective activity.

\section{Introduction}

Tropical convection is a very important atmospheric feature acting firstly on the global water and radiative budgets. It also has a significant effect on the spatial distribution of the trace gases through convective transport. The horizontal extension for tropical convection ranges from a few kilometres for individual clouds to several hundreds of kilometres for convective clusters or organized convective systems. In global atmospheric weather or chemistry models the horizontal resolution is generally not fine enough (typically one to a few degrees) to take into account explicitly the convection process. Thus parameterizations are used to describe convection. They are designed to represent the effect of sub-grid scale convection on its environment. Although many parameterizations have been proposed in the literature in the past (e.g. Arakawa and Schubert, 1974; Tiedke, 1989; Kain and Fritch, 1990; Grell, 1993; Zhang and McFarlane, 1995) it remains an important source of uncertainty in current global models. There is a large variability linked to the different parameterization formulations proposed (adjustment methods, mass-flux methods based on plume ensemble or on bulk formulations). The results of any convection parameterization are also known to be sensitive to the model horizontal and vertical resolutions. Enhanced convective fluxes are provided by finer horizontal resolutions (e.g. Brankovic and Gregory, 2001). The detrainment level depends on the vertical resolution (Pope et al., 2001; Roeckner et al., 2006).

Published by Copernicus Publications on behalf of the European Geosciences Union. 
The transport of tracers by convection is taken into account in global Chemistry Transport Models (CTMs) through the fluxes provided by a convection parameterization. In the tropics, convection is of particular importance in CTMs. It lifts rapidly a significant part of the surface emissions from the lower troposphere into the Tropical Tropopause Layer (TTL) (e.g. Wang et al., 1996; Pickering et al., 1996; Marécal et al., 2006). The TTL is defined as the transitional layer between pure tropospheric and pure stratospheric conditions. We use here the definition proposed recently by Fueglistaler et al. (2009). Its bottom boundary is the level of main convective outflow at the zero radiative level under all sky conditions $(\sim 150 \mathrm{hPa}, 355 \mathrm{~K})$. Its top boundary is the top of the most energetic and intense cumulonimbus which can reach $(\sim 70 \mathrm{hPa}, 425 \mathrm{~K})$. The zero radiative heating level is located within the TTL around $15.5 \mathrm{~km}$ $(360 \mathrm{~K})$. Above this level, trace gases are slowly lifted into the lower stratosphere where they can act on the ozone budget at the global scale. The errors on the fluxes provided by the convection parameterizations lead to uncertainties on the tracer transport and consequently on the spatial distribution of the chemical species in the TTL. Therefore, the evaluation of the transport of tracers by tropical convection in global CTMs is a required step towards foreseen improvements. The approach we propose for assessing the convective tracer transport in CTMs is to use long-duration (15 days to one month) regional (typically $6000 \mathrm{~km} \times 4000 \mathrm{~km}$ ) simulations with a limited-area atmospheric model including tracer transport. We use intermediate horizontal/vertical resolutions $(20-60 \mathrm{~km} / 850 \mathrm{~m})$ between typical CTM resolutions $\left(1^{\circ}-5^{\circ} / 1-2 \mathrm{~km}\right)$ and cloud resolving model (CRM) resolutions ( $\sim 1 \mathrm{~km} / 100-200 \mathrm{~m})$. This regional approach allows for case study comparisons with local measurements from field campaigns or CRM simulations as well as statistical comparisons with CTM results.

The objective of these two papers is to evaluate longduration regional simulations with a limited-area model as a possible tool to produce realistic tracer transport by tropical convection. These simulations could then be used for the assessment of CTMs. Part 1 is devoted to the study of the sensitivity of the regional modelling approach to the choice of parameterization of subgrid scale deep convection. The present paper (Part 2) studies the sensitivity to the model vertical and horizontal resolutions which is a major source of uncertainty for convective tracer transport. The model used is the mesoscale model CATT-BRAMS (Freitas et al., 2009) that is specially designed for tropical studies.

In Part 1, we compared six simulations using the massflux framework proposed by Grell and Dévényi (2002) for subgrid scale deep convection. The first five simulations use five different closure assumptions and the sixth experiment is an ensemble based on these five closures. The model was run for one month in the Maritime Continent area during the pre-monsoon season. Meteorological results do not show large differences between the six simulations on a monthly average basis as well as on shorter timescales, except for rainrates. Scores of surface rainrates are significantly better for three of the simulations with the ensemble parameterization providing the best agreement with TRMM observations. These three experiments also provide significantly more tracer transport in the TTL.

In the present paper, we focus on the effect of spatial resolution on the transport of the same idealized tracers used in Part 1. The issue of the impact of model resolutions on atmospheric simulation results has often been discussed for global (e.g., Sperber et al., 1994; Phillips et al., 1995; Pope et al., 2001) and mesoscale models (e.g. Lane and Knievel, 2005; Smith et al., 2007). Fewer studies have explored the impact of model resolution on tracer transport (Gray 2003, Deng et al., 2004; Wild and Prather, 2006; Rind et al., 2007; Aghedo et al., 2008). Wild and Prather (2006) found a continuous improvement of tropospheric ozone compared to NASA TRACE-B campaign data when varying the horizontal resolution from coarser to finer (T21 down to T106) in a CTM. They also showed that the export of short-lived precursors such as $\mathrm{NO}_{\mathrm{x}}$ by convection is overestimated at coarse resolution. Rind et al. (2007) found using the GISS global circulation model that the vertical resolution has a significant effect on tracer transport. This effect is enhanced when both finer horizontal and vertical resolutions are used. Aghedo et al. (2008) also showed that the tracer transport in the ECHAM5 global circulation model is mostly dependent on the vertical resolution with a faster transport associated with finer resolutions. Using the mesoscale MM5-SCIPUFF model Deng et al. (2004) found an improvement of the statistical skill for interregional tracer transport compared to field data using finer horizontal (down to $12 \mathrm{~km}$ ) and vertical resolutions. A detrimental effect was obtained with further reduction of the horizontal resolution. Gray (2003) conducted a detailed study on a case of extratropical cross-tropopause transport in a tropopause folding event. Its simulations with the UKMO Unified model showed that the transport from stratosphere to troposphere by parameterized processes was dominated by convection. They also found a high sensitivity of the model results to horizontal and vertical resolution. All these studies clearly show that the choice of horizontal and/or vertical resolution in models is an important issue for tracer transport. Compared to previous studies, the present work addresses specifically the issue of the impact of model resolution on tracer transport by tropical convection with a mesoscale model. In particular, the occurrence of overshooting convection is discussed.

In the present paper, the model set-up for the different simulations is given in Sect. 2. Section 3 is devoted to the analysis of the comparison of model results to local measurements. The statistical analysis over the one month simulation period is discussed in Sect. 4. Section 5 concludes this study. 
Table 1. Description of the characteristics of the different simulations.

\begin{tabular}{lll}
\hline Simulation & Horizontal resolution & $\begin{array}{l}\text { Number of vertical layers } \\
\text { (depth in the UTLS) }\end{array}$ \\
\hline REF & $60 \mathrm{~km} \times 60 \mathrm{~km}$ & $56(300 \mathrm{~m})$ \\
HR & $20 \mathrm{~km} \times 20 \mathrm{~km}$ & $56(300 \mathrm{~m})$ \\
CVR & $60 \mathrm{~km} \times 60 \mathrm{~km}$ & $43(850 \mathrm{~m})$ \\
\hline
\end{tabular}

\section{Model set-up}

We ran several simulations with the CATT-BRAMS model (Freitas et al., 2009) using a set of different spatial resolutions (Table 1). The general model description is given in the first paper (Part 1) and not detailed here. The simulations use a setup similar to the simulation called EN discussed in the first part of this series (Part 1) except for horizontal and vertical resolutions. They include one grid covering a $7200 \mathrm{~km}$ by $5000 \mathrm{~km}$ domain ranging from $100^{\circ} \mathrm{E}$ to $160^{\circ} \mathrm{E}$ and from $20^{\circ} \mathrm{N}$ to $20^{\circ} \mathrm{S}$. The model topography and geography of the domain is illustrated in Fig. 1 in Part 1. The simulations last 30 days from the 15 th November 2005 to the 15th December 2005. During this period, evidence of overshooting convection has been shown (Corti et al., 2008). All radiative calculations were done with the Harrington (1997) scheme. We use the one-moment bulk microphysics parameterization which includes the prediction of the mixing ratios of water vapour, cloud water, rain, pristine ice, snow, aggregates, graupel and hail and the concentration of pristine ice (Walko et al. 1995). Shallow convection and deep convection are parameterized following the ensemble parameterization as described in Grell and Devenyi (2002) (see Part 1 for details). This parameterization gives better meteorological results than the other available parameterizations as shown in Part 1.

Initial and boundary conditions are set similarly to the simulations discussed in Part 1. 3D-fields at the initial time for meteorological variables come from ECMWF operational analysis. At the lateral boundaries of the domain a zero gradient condition is used for inflow and outflow. On top of this, a nudging procedure is applied to constraint the model towards ECMWF operational analyses. At the top of domain, we use a rigid lid above $25 \mathrm{~km}$ altitude to damp gravity waves. Soil moisture initialisation is obtained from satellite TRMM precipitation estimates (Gevaerd and Freitas, 2006). Sea surface temperatures (SSTs) are from satellite-derived weekly analyses.

The reference simulation (called hereafter REF) was done with a $60 \mathrm{~km}$ horizontal grid spacing. Note that it is identical to the simulation called EN in Part 1. It includes 56 vertical levels, with a high resolution ( $300 \mathrm{~m}$ depth) between
Table 2. Characteristics of the idealized tracers used in the simulations.

\begin{tabular}{|c|c|c|c|}
\hline Tracer & Lifetime & Initial conditions & Emissions \\
\hline 1 & $6 \mathrm{~h}$ & 0 & $\begin{array}{l}10^{-9} \mathrm{~kg} \mathrm{~m}^{-2} \mathrm{~s}^{-1} \\
\text { over land }\end{array}$ \\
\hline 2 & infinite & 0 & $\begin{array}{l}10^{-9} \mathrm{~kg} \mathrm{~m}^{-2} \mathrm{~s}^{-1} \\
\text { over land }\end{array}$ \\
\hline 3 & $\begin{array}{l}\text { Infinite if } \theta>380 \mathrm{~K} \\
6 \mathrm{~h} \theta<380 \mathrm{~K}\end{array}$ & $\begin{array}{l}1 \mathrm{ppt} \text { if } \theta>380 \mathrm{~K} \\
0 \mathrm{ppt} \text { if } \theta<380 \mathrm{~K}\end{array}$ & No emissions \\
\hline 4 & infinite & $\begin{array}{l}1 \mathrm{ppt} \text { if } \theta>380 \mathrm{~K} \\
0 \mathrm{ppt} \text { if } \theta<380 \mathrm{~K}\end{array}$ & No emissions \\
\hline
\end{tabular}

$14.5 \mathrm{~km}$ and $19 \mathrm{~km}$ altitude. A high resolution simulation (called hereafter HR) was run using the same vertical levels as the REF simulation but using a $20 \mathrm{~km}$ horizontal grid spacing. A simulation with a $60 \mathrm{~km}$ horizontal resolution but with a coarse vertical grid spacing (CVR) was also run. It includes only 43 vertical levels with a resolution of 850 meters between 14.5 and $19 \mathrm{~km}$. The transport of tracers is activated in all the simulations. We chose the same set of four idealized tracers as in Part 1 to characterize the fluxes between the troposphere and the stratosphere (see Table 2).

\section{Analysis of the case study of the 23rd November 2005}

In this section we analyse the results from the different simulations with respect to campaign measurements for one case study to evaluate simulation performances. During the simulation period several DLR-Falcon and Geophysica (M55) flights were done around Darwin (Australia) in the framework of the SCOUT-O3 field campaign (Vaughan et al., 2008; Brunner et al., 2009). Most of the flights were around the Hector convection events regularly occurring over the Tiwi Islands. Some of them were extended flights planned for study of the surrounding regions: 23, 25, 29 November and 5 December. Since the model simulations cover a large area, a comparison with the extended flights was preferred for the model evaluation. On the 5th December, the aircraft flew southward only partially within our domain. Therefore this flight has not been used. This is the same for the beginning of the $29^{\text {th }}$ November flights for legs done before 08:30 UT. A comparison was done with the other extended flights on the 25th November showing consistent results. To illustrate the model behaviour we chose the case of the $23^{\text {rd }}$ November.

On the 23rd, the Geophysica and the Falcon flew over the Timor Sea to probe the TTL in details. The flight paths are displayed in Fig. 14 in Brunner et al. (2009). Both aircraft flew along north-east oriented legs perpendicular to the mean flow expected to be north-westerly in the TTL. Flying back and forth along the same line twice, the Geophysica sampled around cold point tropopause at four different levels: 



Fig. 1. Comparison between the Geophysica meteorological data and the three model simulations for the 23rd November 2005. (a) Temperature $(\mathrm{K}),(\mathbf{b})$ horizontal wind speed $\left(\mathrm{m} \mathrm{s}^{-1}\right),(\mathbf{c})$ wind direction $\left(^{\circ}\right)$ and (d) specific humidity $\left(\mathrm{g} \mathrm{kg}^{-1}\right)$. The black lines are for the aircraft measurements and the colored lines for the model results. The dashed line is the model altitude in $\mathrm{m}$.

one significantly below the cold point level at $\sim 15.6 \mathrm{~km}$ (leg 1 ), two close to the cold point tropopause at $\sim 17.5 \mathrm{~km}$ (leg 3 ) and $\sim 16.4 \mathrm{~km}$ (leg 4 ), and one level well above at $\sim 18.3 \mathrm{~km}$ (leg 2).

Figures 1 and 2 show the airborne measurements and model results for temperature, horizontal wind speed and direction, and specific humidity, for the Geophysica and the Falcon flights. The model results are interpolated at the location and time of the measurements using an hourly time resolution for the model outputs. Whichever set-up used, the model provides too warm temperatures around the cold point tropopause and too cold temperatures in the troposphere up to $14 \mathrm{~km}$. There is only a slight dependence of the model results to vertical or horizontal resolution (Figs. 1a and 2a) with maximum differences of about $1 \mathrm{~K}$.

The horizontal wind speed and direction simulated by the three runs along the aircraft trajectories are generally in good agreement with measurements (Figs. 1b, 1c, 2b and 2c). They tend to underestimate the wind speed compared to Geophysica. The model values are significantly closer to the Geophysica measurements when using a finer vertical or a finer horizontal resolution. HR run gives the best values, with differences up to $2 \mathrm{~m} \mathrm{~s}^{-1}$ with CVR run. HR and REF also give a better agreement for the wind direction with the Falcon data than CVR. HR provides the best results with differences up to $15^{\circ}$ with CVR. CVR only provides better results for the wind speed for Falcon legs 2 and 3.

For specific humidity the Geophysica and Falcon measurements (Figs. 1d and 2d) are generally well modeled in the three simulations. There is a slight model overestimation for all Geophysica legs above the cold point tropopause. There in an improvement between the modeled specific humidity values provided by the HR simulation and to a lesser extent by the REF simulation compared to CVR. Two strong peaks were observed by both aircraft (e.g. around $16000 \mathrm{~s}$ and $18000 \mathrm{~s}$ in the Geophysica flight) and identified as the signature of deep convective events. They are not captured by the model even using the HR $20 \mathrm{~km}$ horizontal resolution.

In summary the model shows a generally good consistency with the aircraft observations. The differences between the three simulations are generally significant but smaller than the differences with aircraft data. HR gives better results than REF and CVR simulations. This shows that there is a positive impact of using both fine vertical and horizontal resolutions. HR provides more variability of all meteorological variables than the other two simulations although less than in the observations. The general lack of variability of the model results can be attributed to two facts. Firstly 

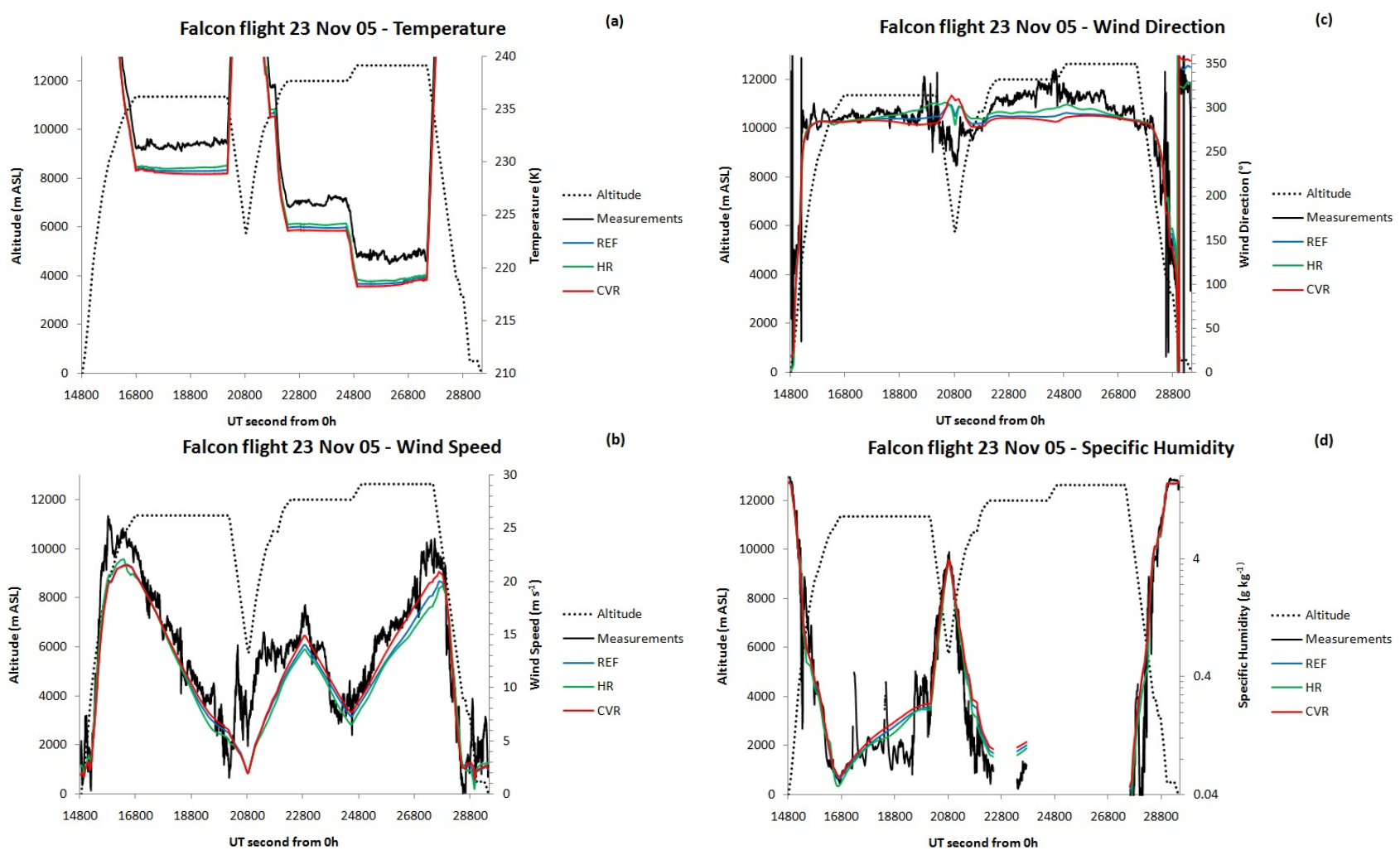

Fig. 2. Same as Fig. 1 but for the Falcon data of the 23rd November 2005.

the model horizontal resolution is large (even in HR) compared to most of the small scale structures that are captured by the aircraft measurements. Secondly the model is not always able to trigger convection exactly when and where observed whatever resolutions are used (see statistical results in Sect. 4). There is a local impact on meteorological variables that is provided by the convection parameterization and depends on the model resolution. But it is generally missed in the model-measurement comparison because of the modelmeasurement mismatch on convection location/time.

\section{Statistical analysis}

In the perspective of a comparison with the tracer transport in CTMs it is necessary to characterize the model behaviour on a statistical basis using the whole one month results. Firstly the meteorological fields for the three simulations are discussed against measurements (TRMM products and a series of radiosoundings). Secondly the idealized tracer distribution is analysed.

\subsection{Model comparison with TRMM surface rainrates}

We compared the surface accumulated rainfall rates obtained with REF, HR and CVR to those estimated by TRMM. The dataset used is 3 -hourly and $0.25^{\circ} \times 0.25^{\circ}$ resolution and was produced by the 3B42 algorithm (Huffman et al., 2007, http://trmm.gsfc.nasa.gov). Note that the same dataset was used in Part 1 to evaluate the sensitivity to convection parameterizations. Fig. 3 shows the daily evolution of surface precipitation rates averaged over the simulation domain. The three runs correctly model the time variations with an increase of $\sim 1.5 \mathrm{~mm}$ day $^{-1}$ between the beginning (16th of November) and the end (14th of December) of the simulation period. This increase corresponds to the establishment of the monsoon in the Maritime continent. HR provides values significantly closer to observations. CVR gives a more flattened evolution and larger differences with TRMM.

Figure 4a gives the mean surface rain rates (in mm day ${ }^{-1}$ ) estimated by TRMM during the one-month simulation period. The mean surface rainrates provided by the three simulations are shown in Fig. $4 \mathrm{~b}$ to $d$. The spatial distribution of the rainrates is generally consistent with the TRMM-based values. However, there are significant differences between the three runs. REF correctly locates high precipitation areas and the associated intensities but underestimates low precipitation values. This difference, as discussed in Part 1, can be partly attributed to a large uncertainty on light precipitation in the 3B42 TRMM product. This possibly leads to an overestimation of light surface precipitation. This is also partly 


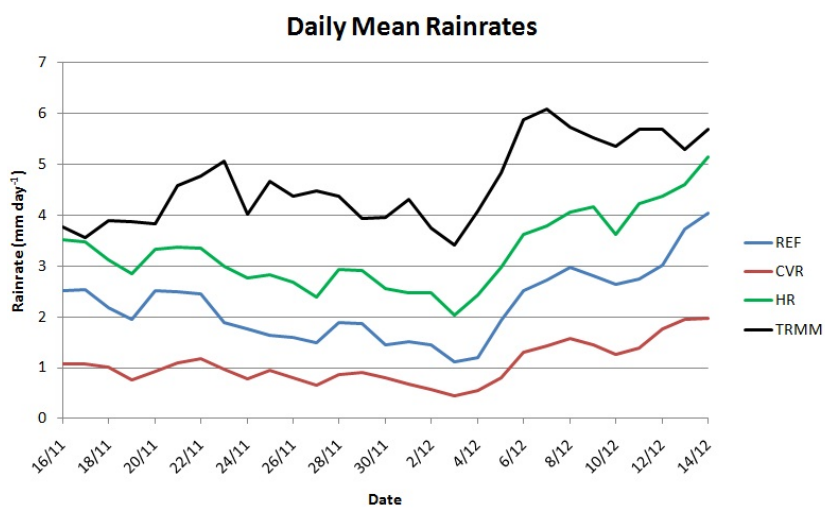

Fig. 3. Time evolution of the daily mean rainrate averaged over the simulation domain in $\mathrm{mm} \mathrm{day}^{-1}$.

due to an underestimation of light precipitation prediction in the model. When refining the horizontal resolution (HR), the model is able to better reproduce the intensity and spatial distribution of the surface rainrates compared with observations. Low to medium rainrates are better represented, especially over the north of Australia. The results provided by the simulation with a coarser vertical resolution (CVR) show large differences with REF and HR simulations and with the TRMM-based observations. Areas of high rainrates are correctly located but underestimated by about $5 \mathrm{~mm}_{\text {day }}{ }^{-1}$. Medium and low precipitation rainrates are largely underestimated especially over sea in the North of Australia.

The distribution plot of the model surface rainrates versus TRMM (Fig. 5) corroborates these conclusions. The three runs show a tendency to underestimate low rainrates under $10 \mathrm{~mm} \mathrm{day}^{-1}$ that are associated to stratiform precipitation and to light convective precipitation $\left(5-10 \mathrm{~mm} \mathrm{day}^{-1}\right)$. Increasing spatial resolution in the horizontal and the vertical allows the model to simulate more intense precipitation associated to convection events $\left(>20 \mathrm{~mm} \mathrm{day}^{-1}\right)$. It also decreases the underestimation of low to medium rainrates.

In order to analyse more precisely the model results, we calculated precipitation scores: Equitable Threat Score, Probability Of Detection and False Alarm Ratio. Equitable Threat Score evaluates how well modelled raining events correspond to observed raining events, according for hits due to chance. Probability Of Detection tells us what fraction of the observed raining events is correctly modelled. False Alarm Ratio highlights the fraction of the modelled events that do not occur. Calculation methods and minimum/maximum values for these scores are given in Fig. 6a and results in Fig. 6b to d. Equitable Threat Score for the three resolutions ranges from $\sim 0.5$ to 0.65 . This highlights the generally good behaviour of the model to forecast surface precipitation as already shown in Part 1. HR provides higher Equitable Threat Score during the first part of the simulation indicating a better representation of the less active convection period. This is correlated with a higher Probability Of Detection given by HR. HR Probability Of Detection is $\sim 30 \%$ better than CVR and REF ones during the first period of the simulation and $\sim 5 \%$ after. However, HR also provides a higher False Alarm Ratio during the whole period. HR simulates well the occurrence of convection events (high Probability Of Detection) but also slightly overestimate them (relatively high False Alarm Ratio).

These results indicate that both the vertical and the horizontal resolution have an important impact on the representation of surface precipitation. At each grid point the convection parameterization determines if convection is triggered or not. If yes, it calculates the model level of the top of convection. When using a coarse vertical resolution in the TTL the convection parameterization can only choose over a few model levels for convection top. On average therefore it provides a lower top height of convection and consequently weaker vertical fluxes. This is consistent with previous studies showing a dependency of the detrainment level with vertical resolution (Pope et al., 2001; Roeckner et al., 2006). A simulation with a fine horizontal resolution provides meteorological fields with more variability. This favours the occurrence locally of more instable conditions needed for convection triggering. This allows the model to simulate more intense convection. This is in agreement with previous results (e.g. Brankovic and Gregory, 2001).

\subsection{Comparison with radiosounding data}

The model results have been compared with a series of 12-hourly launched from Manus Island, Papua New-Guinea $\left(147^{\circ} \mathrm{E} ; 2^{\circ} \mathrm{S}\right.$ ) within the ARM program (Atmospheric Radiation Measurement, http://www.arm.gov/) during the simulation period. Table 3 gives the mean bias (measurement - model) and the standard deviation of the bias between the radiosoundings and the three simulations for temperature, wind speed and direction and specific humidity. To calculate these statistics, radiosounding data were averaged over the model vertical levels and biases for individual Manus soundings were then averaged. The specific humidity was preferred to the relative humidity because the errors on the relative humidity include not only the uncertainties on the specific humidity but also on temperature. Moreover since the specific humidity decreases with altitude, the specific humidity statistics given in Table 3 are less weighted by the upper tropospheric levels that are known to be dry biased in the radiosoundings (http://www.arm.gov/ publications/tech_reports/handbooks/sonde_handbook.pdf).

All three simulations provide generally low biases showing the good forecast skill of the model. The temperature biases and standard deviations are related to an underestimation in the troposphere, except in the TTL. In this layer the model overestimates the cold point temperature which is very low with a sharp gradient in this geographical area. For the temperature bias at the cold point the $300 \mathrm{~m}$ vertical resolution used in REF and HR is not sufficient to reproduce 




(a)



(c)



(b)



(d)

Fig. 4. Mean surface rainrate in $\mathrm{mm} \mathrm{day}^{-1}$ from 15 November 2005 to 15 December 2005 for (a) TRMM and (b) the model REF simulation, (c) CVR simulation and (d) HR simulation.

Table 3. Mean bias and standard deviation of the bias between radiosoundings at Manus and the three simulations for temperature $(\mathrm{K})$, wind speed $\left(\mathrm{ms}^{-1}\right)$ and direction $\left(^{\circ}\right)$ and specific humidity $\left(\mathrm{g} \mathrm{kg}^{-1}\right)$.

\begin{tabular}{lllll}
\hline Manus & & REF & HR & CVR \\
\hline Temperature & Mean Bias & -0.307 & -0.200 & -0.455 \\
& Std Dev & 1.108 & 1.065 & 1.095 \\
\multirow{2}{*}{ Wind Speed } & Mean Bias & -1.322 & -1.122 & -1.523 \\
& Std Dev & 3.185 & 3.134 & 2.916 \\
Wind Dir. & Mean Bias & 7.724 & 4.261 & 4.581 \\
& Std Dev & 62.78 & 60.81 & 54.70 \\
Specific & Mean Bias & -0.088 & -0.085 & -0.114 \\
Humidity & Std Dev & 0.541 & 0.524 & 0.535 \\
\hline
\end{tabular}

the very sharp gradient observed. The wind speed biases are mainly related to an underestimation by the model of the wind speed and its large gradients in the TTL. The positive water vapour bias indicates an underestimation by the model of the water vapour conversion into precipitation. The vertical profiles of temperature, wind and water vapour are partly driven in the simulation by the convective activity. It induces a warming by condensation and the conversion of water vapour into precipitation in the troposphere below the TTL, strong outflows and a cooling above convection. All the model biases indicate an underestimation of the convective intensity and frequency in the model. HR gives the lowest biases and standard deviations and therefore better meteorological fields. Using a fine horizontal resolution provides more active convection (as shown by the results from the TRMM analysis) corresponding to stronger updraft/outflows and to more precipitation. This leads to a larger impact in HR fields improving the model statistics compared to radiosounding data. The interpretation of the comparison of CVR against REF has to be done keeping in mind that the CVR statistics are calculated on a smaller number of levels. This means that the mean profile calculated using the radiosounding data for CVR is smoother in the upper troposphere and lower stratosphere. Nevertheless REF generally gives better statistical results than CVR. This indicates an improvement when using a fine vertical resolution in the TTL. This is linked to convection which is more active in REF as shown in Sect. 4.1.

In summary all these results are consistent with the TRMM analysis. Using fine vertical and horizontal 

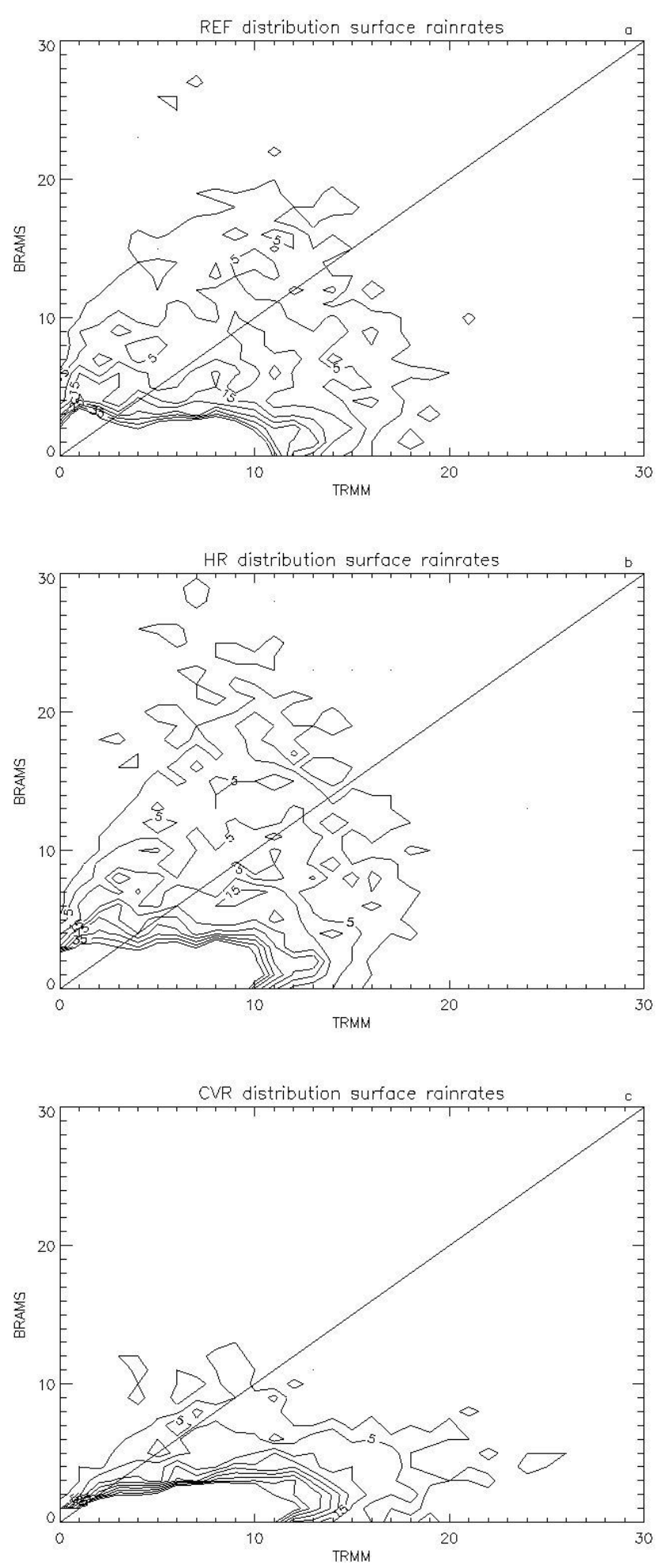

Fig. 5. Distribution of model surface rainrate versus TRMM averaged over the whole period for (a) REF, (b) HR, (c) CVR.

\begin{tabular}{|c|c|c|c|}
\hline \multicolumn{4}{|c|}{\begin{tabular}{|c|c|c|c|} 
& \multicolumn{2}{|c}{ FORECASTED } \\
\multirow{2}{*}{ OBSERVED } & No & No & YES \\
\cline { 2 - 5 } & No & B \\
\cline { 2 - 5 } & YES & C \\
\end{tabular}} \\
\hline MEANING & INDEX & RANGE & $\begin{array}{l}\text { IDEAL } \\
\text { VALUE }\end{array}$ \\
\hline $\begin{array}{l}\text { Overestimation/ } \\
\text { underestimation }\end{array}$ & $B I A S=\frac{B+D}{C+D}$ & {$[0, \infty]$} & 1 \\
\hline $\begin{array}{l}\% \text { correctly } \\
\text { forecasted events }\end{array}$ & $P O D=\frac{D}{C+D}$ & {$[0,1]$} & 1 \\
\hline False alarme ratio & $F A R=\frac{B}{B+D}$ & {$[0,1]$} & 0 \\
\hline Eq. Threat Scores & ETS & {$[-1 / 3,1]$} & 1 \\
\hline $\begin{array}{l}\% \% \text { correctly } \\
\text { forecasted diot- } \\
\text { events (specificity) }\end{array}$ & $1-P O F D=\frac{A}{B+A}$ & {$[0,1]$} & 1 \\
\hline
\end{tabular}

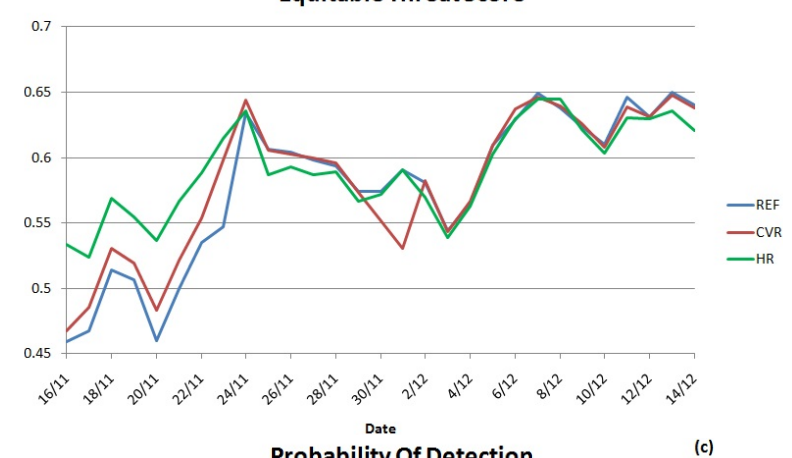

Probability Of Detection

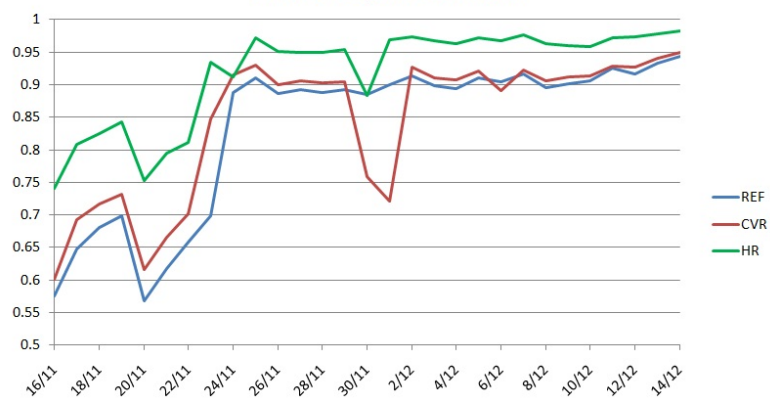

False Alarm Rate

(d)

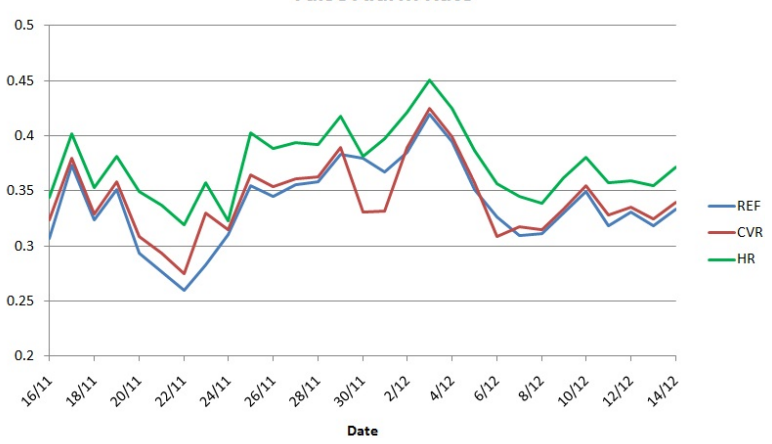

Fig. 6. (a) Definition and minimum/maximum values of Equitable Threat Score, Probability Of Detection and False Alarm Ratio. Daily evolution of (b) ETS, (c) POD and (d) FAR during the simulation period for the three runs. 
Table 4. Mean tracer fluxes integrated over the simulation domain and during the whole simulation period using hourly model outputs.

\begin{tabular}{lllll}
\hline & & REF & HR & CVR \\
\hline Tracer flux at 14 km & Tracer 1 & 0.0036 & 0.0147 & 0.0002 \\
$\left(10^{-9} \mathrm{~kg} \mathrm{~m}^{-2} \mathrm{~s}^{-1}\right)$ & Tracer 2 & 0.0645 & 0.1911 & 0.0134 \\
\hline
\end{tabular}

6h lifetime idealised tropospheric tracer mixing

(a) ratio profile

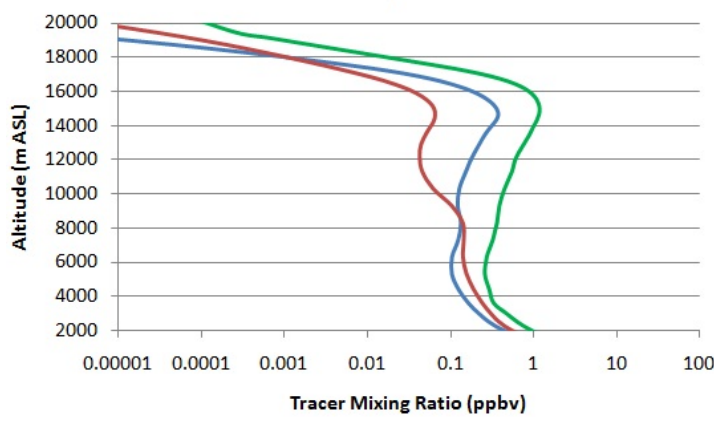

Inifinite lifetime idealised tropospheric tracer mixing ratio profile

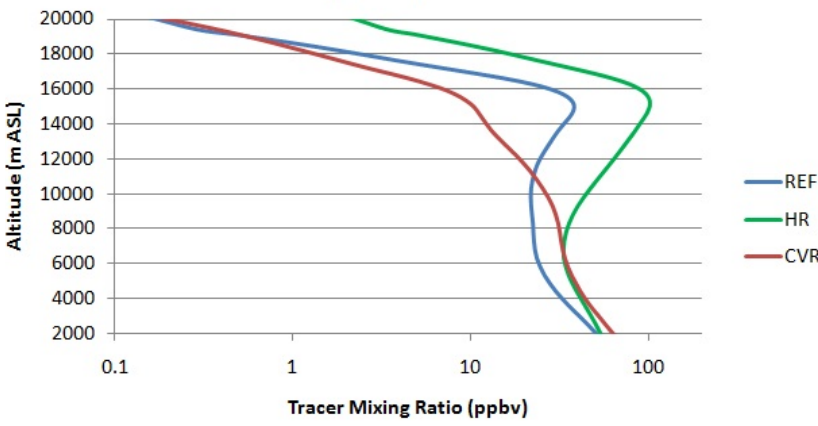

Fig. 7. Tracer volumic mixing ratio profiles averaged over the model domain and over the one month simulation period using 3hourly model outputs for (a) Tracer 1 and (b) Tracer 2.

resolutions modifies the meteorological fields and gives model results closer to meteorological observations.

\subsection{Mean tracer mixing ratio vertical profiles}

Figure 7 shows the mean mixing ratio profiles averaged over the model domain and over the one month simulation period using 3-hourly outputs for Tracer 1 (tropospheric tracer with a $6 \mathrm{~h}$ lifetime) and Tracer 2 (tropospheric tracer with an infinite lifetime). In Fig. 7 the mean cold point level $(\sim 17.3 \mathrm{~km}$ altitude), TTL bottom $(\sim 14 \mathrm{~km})$ and TTL top $(18.9 \mathrm{~km})$ from the simulations have been displayed. The definition proposed recently by Fueglistaler et al. (2009) has been used to determine the TTL top and bottom from the simulation results. 6h lifetime stratospheric idealised tracer mixing ratio profile

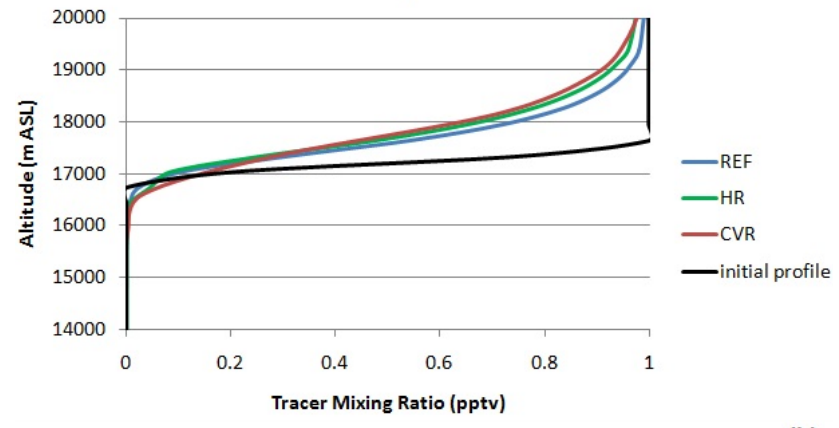

infinite lifetime idealised stratospheric tracer mixing ratio profile

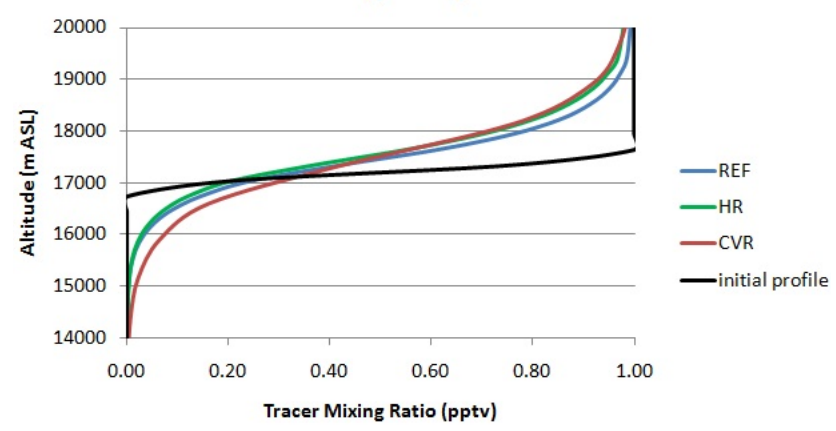

Fig. 8. Same as Fig. 7 but for Tracer 3 and 4 (stratospheric tracers). The dark line is the mean vertical profile at the initial time of the simulation.

In Fig. 7 the shape of the simulated profiles for both tracers is typical of convective areas: large values in the low troposphere decreasing in the mid-troposphere and increasing in the upper troposphere. The maximum value is reached around $15 \mathrm{~km}$ altitude. Above, there is a rapid decrease down to very low values at $20 \mathrm{~km}$ altitude. The three profiles also exhibit a relative maximum around $8 \mathrm{~km}$ altitude for Tracer 1. This is linked to the preferred altitudes for the convective outflows in the Grell and Dévényi (2002) convection parameterization. This local maximum is smoothed in Tracer 2 mean profile by the large scale advection and diffusion.

The comparison between REF and HR results shows that HR provides larger amounts of both tracers in the upper troposphere with a ratio of $\sim 3.3$ for Tracer 1 and $\sim 2.7$ for Tracer 2 at $15 \mathrm{~km}$ altitude. Increasing the horizontal resolution provides stronger and more frequent convection events as discussed in the analysis of the surface rainrates. This leads to an increase of the tracer transport from the lowest model levels into the TTL. The effect of the increase of convective activity in HR is also visible on the highest levels which exhibit larger values above $15 \mathrm{~km}$ altitude for Tracer 1 . Since this tracer has a very short lifetime, this indicates that the HR configuration provides more frequent 
Mean vertical speed evolution at TTL bottom (14 km)

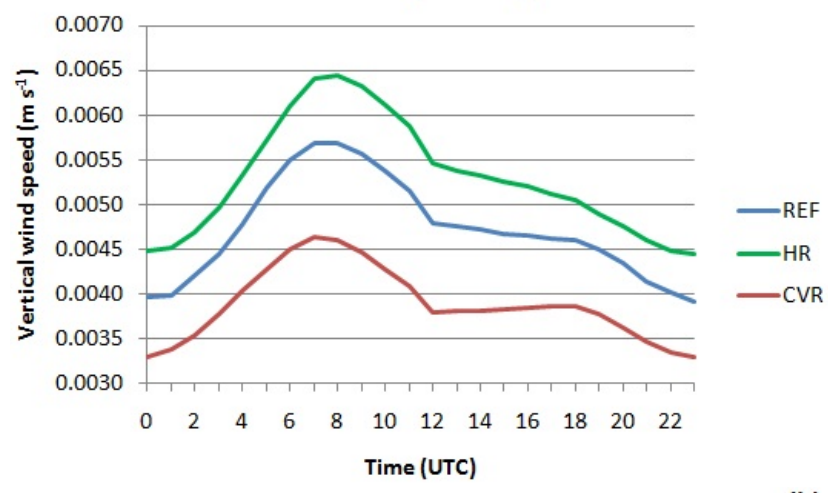

Mean vertical speed evolution cold point tropopose (17.3 km)

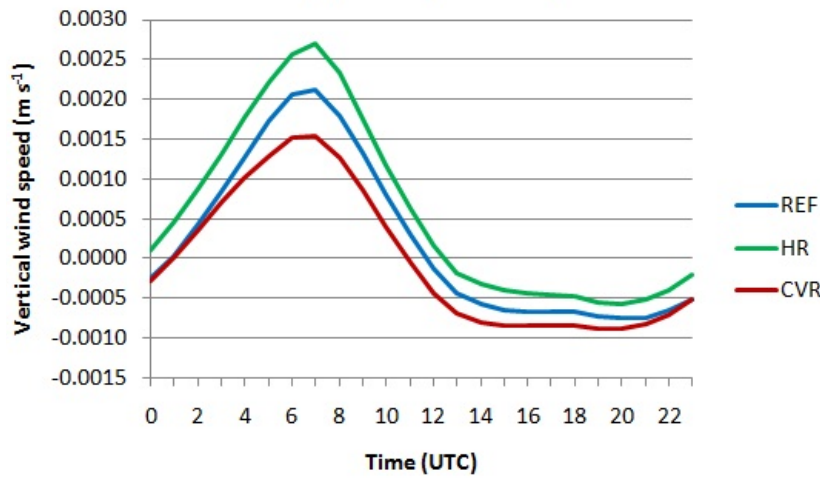

Fig. 9. Diurnal evolution of the vertical wind speed averaged over the model domain at (a) $14 \mathrm{~km}$ and (b) $17.3 \mathrm{~km}$ altitude.

and/or more efficient overshooting above the dynamical barrier of the mean cold point level. This effect is more pronounced on Tracer 2 that undergoes diffusion and slow radiative uplift once it has reached the TTL.

The comparison between REF and CVR for Tracer 1 and Tracer 2 (Fig. 7) shows that CVR provides much lower tracer transport in the TTL. Both tracers are mainly vertically distributed from the surface to $9 \mathrm{~km}$ altitude in CVR. This simulation is not able to uplift efficiently tropospheric tracers. This indicates that the tracer transport in the convection parameterization is very sensitive to vertical resolution in the TTL. For the same convective instability in the low levels in REF and CVR, CVR determines a lower cloud top altitude. This leads to an important underestimation of the tracer transport in the TTL. The model diffusion and advection in CVR acts on Tracer 2 once lifted by convection but does not modify the general shape of the vertical mean distribution.

Figure 8 shows the mean mixing ratio profiles for Tracer 3 and Tracer 4 (idealised stratospheric tracer with a $6 \mathrm{~h}$ and an infinite lifetime) averaged similarly to Tracers 1 and 2 in Fig. 7. The three simulations for both tracers provide a similar shape: values close to 1 down to the top of the TTL ( $\sim 19 \mathrm{~km}$ altitude), a sharp decrease below down to $17 \mathrm{~km}$ and a smoother decrease down to $14-15 \mathrm{~km}$ where it reaches zero. The comparison with the initial mean profile indicates that the $6 \mathrm{~h}$ lifetime stratospheric tracer is partly mixed with TTL air ( $>0.4 \mathrm{ppt}$ at the cold point level). This shows that the convection parameterization is able to transport significant amounts of stratospheric tracers below the dynamical barrier of the cold point level. CVR provides a smoother profile because of its $850 \mathrm{~m}$ vertical resolution. Below $16.9 \mathrm{~km}$ altitude HR provides larger mixing ratios compared to REF. This is likely related to more frequent overshoots in HR leading to more irreversible mixing of the stratospheric tracer in the TTL. For the infinite lifetime tracer there are almost no differences between REF and HR because the dominant process is mixing by diffusion. In CVR which has less vertical levels, the mixing is done over larger depths than in REF and HR leading to a deeper mixing layer. This is consistent with Brunner et al. (2005) who showed that sharp tracer gradients across the tropopause are usually not well represented in the models with an excessive mixing between tropospheric and stratospheric air.

\subsection{Diurnal evolution of the mean vertical speed and tracer fluxes}

To get a better understanding of these results we analyse the differences between the three simulations for the vertical wind speed and the tracer fluxes in the TTL. The vertical wind speed in the TTL is an important variable acting in the exchanges between the troposphere and the stratosphere. Species lifted up from ground level by deep convection may pass eventually above the cold point level depending of the vertical motions. Figure 9 shows the diurnal evolution of the monthly-mean vertical wind speed for the three simulations respectively at $14 \mathrm{~km}$ (TTL bottom) and $17.3 \mathrm{~km}$ (cold point level) using hourly model outputs. The TTL bottom is chosen because it is the limit from which the tracers can be transported in the stratosphere. The cold point level is chosen since it is a dynamical barrier that convection can sometimes cross allowing an irreversible transport of the tropospheric tracers to the lower stratosphere.

At the TTL bottom height (Figs. 9a) the mean diurnal evolution of vertical wind speed can be divided in two parts. Between 00:00 UT and 12:00 UT, the vertical speed varies according to the convective activity, with a maximum around 08;00 UT. The mean values are calculated over a longitude range of $60^{\circ}$ where the maximum of convective activity occurs at the same local time but different UT times. This leads to a smoothing of the maximum. After 12:00 UT, the vertical wind speed is almost constant and positive. The three simulations exhibit differences in the mean vertical wind speed values but show the same diurnal evolution. Increasing the resolution in the vertical or in the horizontal gives higher speeds as discussed in Sect. 3. This means that tropospheric 


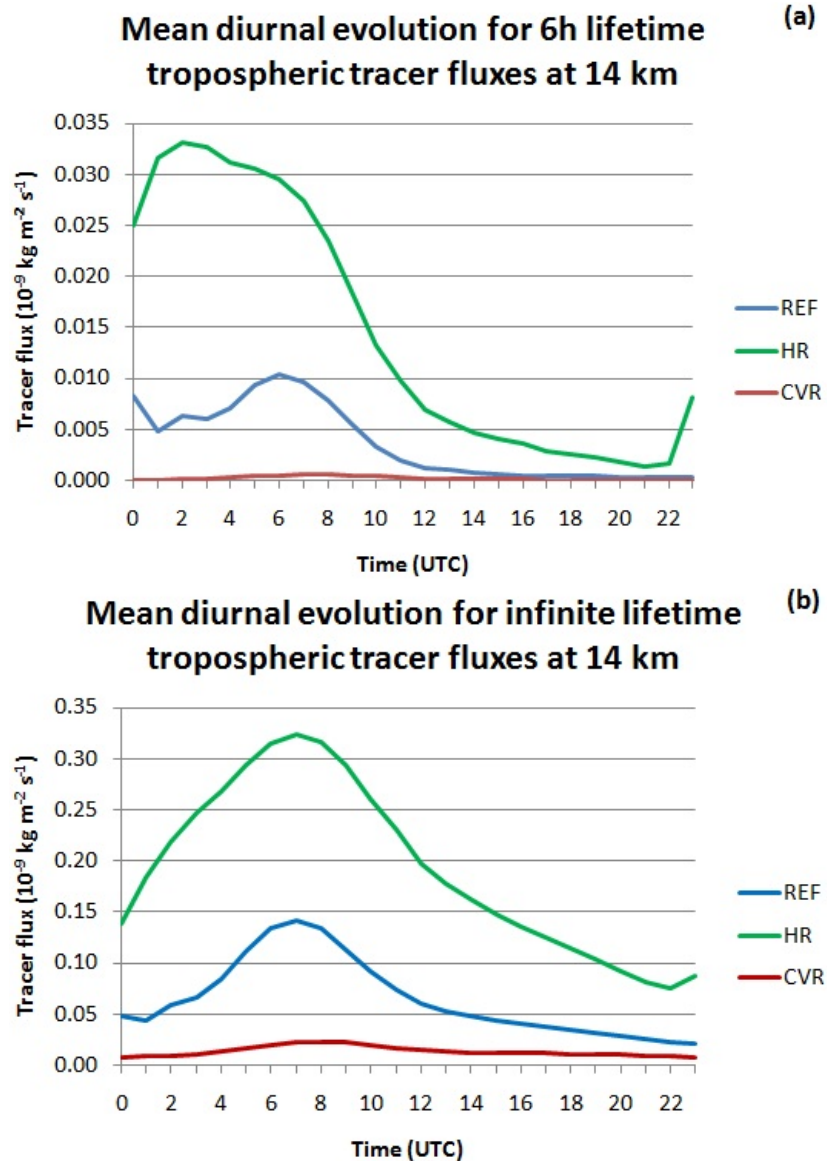

(a)

Mean diurnal evolution for $6 \mathrm{~h}$ lifetime

(c) tropospheric tracer fluxes at $\mathbf{1 7 . 3} \mathbf{~ k m}$

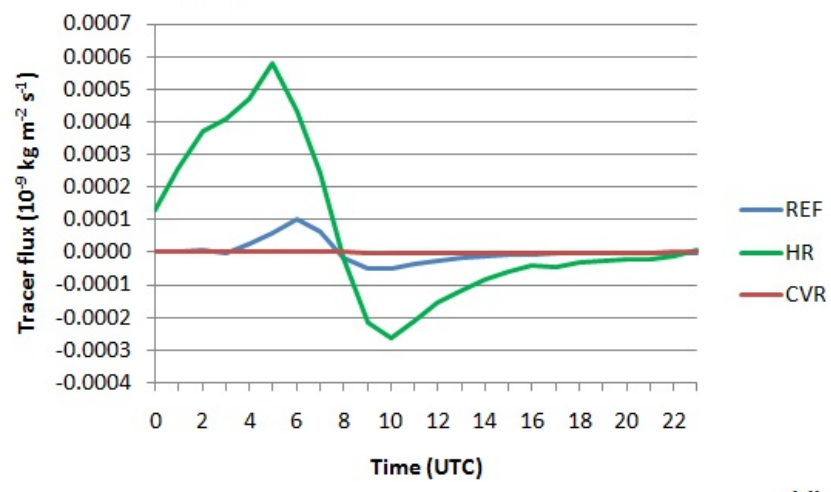

Mean diurnal evolution for infinite lifetime tropospheric tracer fluxes at $\mathbf{1 7 . 3} \mathbf{~ k m}$

(d)

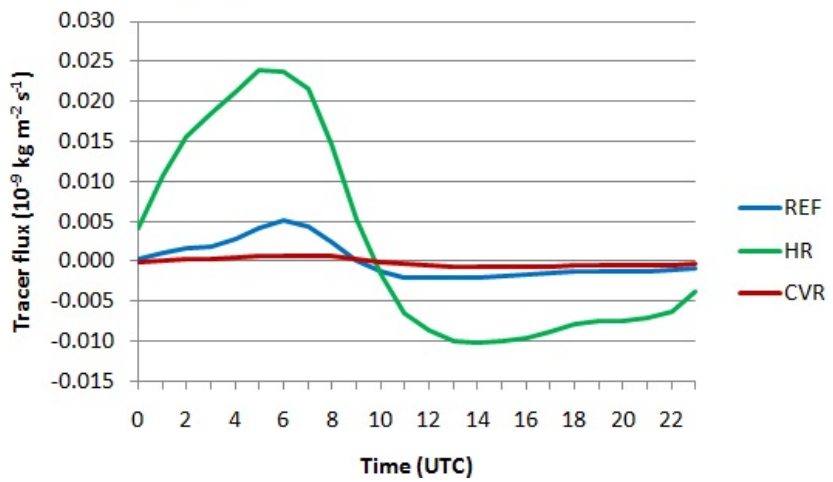

Fig. 10. Diurnal evolution of the mean vertical Tracer 1 and 2 fluxes over the model domain at $14 \mathrm{~km}$ and $17.3 \mathrm{~km}$ altitude.

air masses enter the TTL in all simulations but the amount is directly related to the resolution used.

The same shape for the diurnal vertical wind speed evolution is found at the cold point level (Figs. 9b) but with some differences in the intensity. Between 00:00 UT and 12:00 UT the vertical speed is positive with a peak at 08;00 UT and its intensity is around 3 times lower than at $14 \mathrm{~km}$. The dependence with the vertical and horizontal resolutions is still present with higher speeds when refining the resolution. This is linked to an enhancement of the convective activity (frequency and intensity). On the second part of the day, there is subsidence of the air in all simulations. Thus air masses pass above the cold point level when local convection is established and partially go down during local night. The mean vertical wind speed is positive over the whole day for REF and $\mathrm{HR}\left(2.2 \times 10^{-4} \mathrm{~m} \mathrm{~s}^{-1}\right.$ and $5.7 \times 10^{-4} \mathrm{~m} \mathrm{~s}^{-1}$ respectively), and negative for CVR $\left(-2.1 \times 10^{-5} \mathrm{~m} \mathrm{~s}^{-1}\right)$. For CVR radiative cooling at night is dominant.

To quantify the tracer transport between the troposphere and the stratosphere, the mean fluxes for Tracers 1 and 2 are calculated at two altitudes in the TTL: at the TTL bottom level $(14 \mathrm{~km})$ and at the cold point level $(17.3 \mathrm{~km})$. Results are represented in Fig. 10. The same fluxes at $17.3 \mathrm{~km}$ for Tracers 3 and 4 are shown in Fig. 11. The tracer flux through the TTL depends on the vertical wind speed discussed above but also on the tracer mixing ratio.

Tropospheric tracer fluxes at $14 \mathrm{~km}$ altitude are positive consistent with the vertical wind speed. For the three simulations, the maximum fluxes for both tropospheric tracers are found around 07 UT close to the maximum of vertical wind speed. This indicates that deep convection activity is driving the tracer transport in the upper troposphere. The tropospheric tracer amount entering the TTL depends on the model resolution. HR provides the greatest fluxes for both tropospheric tracers. The fluxes simulated in REF are $\sim 3$ times lower and CVR ones are close to zero. The tracer fluxes depend not only on the vertical wind speed but also on the vertical distribution of the tracers both depending on the convection parameterization. Using a coarse vertical resolution reduces on average the altitude of the convection outflow down to heights usually below $14 \mathrm{~km}$. Tracer 2 fluxes are larger than Tracer 1 fluxes. This can be attributed to the $6 \mathrm{~h}$ lifetime leading to partial tracer depletion before reaching the TTL bottom. The integrated values (see Table 4 ) over the 


\section{Mean diurnal evolution for $6 \mathrm{~h}$ lifetime} stratospheric tracer fluxes at $\mathbf{1 7 . 3} \mathbf{~ k m}$

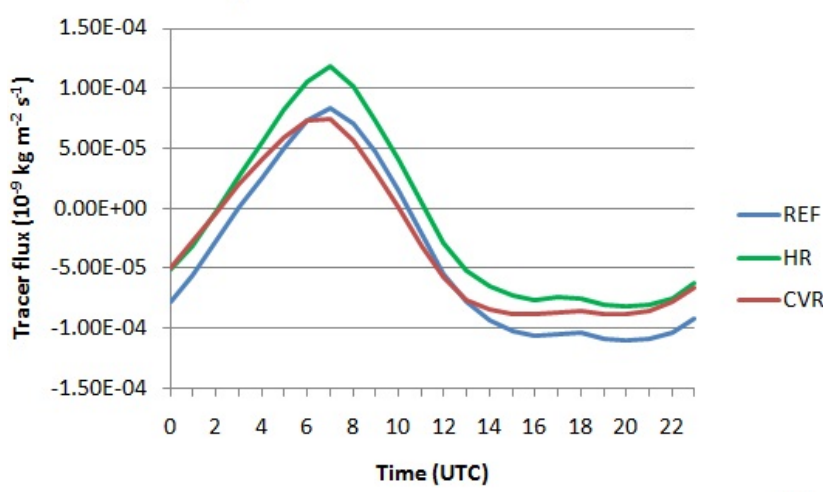

Mean diurnal evolution for infinite lifetime stratospheric tracer fluxes at $17.3 \mathrm{~km}$

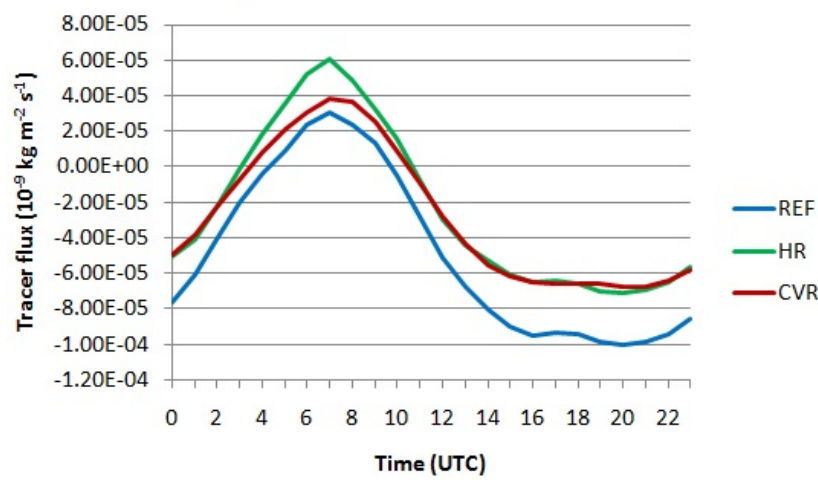

Fig. 11. Same as Fig. 10 but for Tracer 3 and 4 (stratospheric tracers).

whole day for both tracers are significantly larger by a factor of 3-4 for HR and very low for CVR compared to REF. The differences in the fluxes provides by the convection parameterization for different model resolutions have a major impact on the magnitude of the troposphere to stratosphere transport of tracers.

The shape of the diurnal evolution of the fluxes is different at the cold point level. We still observe a maximum at 07:00 UT but a negative minimum is also simulated in the afternoon linked to average downward motions. CVR always simulates very low fluxes meaning that a very small amount of tracers go through the cold point level. For REF and HR, tracer fluxes are well correlated with the convection activity in the model. Before 10:00 UT, the tropospheric tracers are passing across the cold point from troposphere to stratosphere. After 10:00 UT, fluxes oriented from stratosphere to troposphere are found. The integrated values over the whole day (not given) for both tracers are very low for all three simulations. This indicates a slow rate of tracer transport from troposphere to stratosphere. HR values for Tracer 1 are larger than REF confirming that HR transports more tropo- spheric tracer at the cold point level. This could be explained by overshooting convection that occurs in HR.

For the stratospheric tracer fluxes (Fig. 11) the three simulations also show a diurnal cycle with maximum occurring around 07 UT. Between $\sim 03: 00$ UT and $\sim 11$;00 UT, fluxes are positive while they are negative at other times. Integrated values over the day for both stratospheric tracers are negative but almost equal to zero. This indicates that transport of stratospheric tracer is small although slightly more important in HR due to the occurrence of occasional overshoots.

\section{Conclusion}

Tropical convection is a major source of uncertainty in the modelling of transport processes of chemical species in global CMTs. Compared to CTMs, mesoscale models use on-line dynamic fields and finer vertical and horizontal resolutions. They can be used to bridge the gap between the typical small convection scale with the global model scale. In this context the objective of these papers was to evaluate long-duration regional simulations with the mesoscale model CATT-BRAMS with idealised tracers as a possible tool to produce realistic tracer transport by tropical convection. In Part 1, we analysed the impact of different deep convection parametrizations. In the present paper (Part 2), we studied the impact of the vertical and horizontal resolution on this transport. For this purpose three one-month simulations over a $60^{\circ}$ longitude $\times 40^{\circ}$ latitude domain in the Maritime Continent were run (i) with a $60 \mathrm{~km}$ horizontal grid spacing and a $300 \mathrm{~m}$ vertical grid spacing in the TTL, (ii) with a $20 \mathrm{~km}$ horizontal grid spacing and a $300 \mathrm{~m}$ vertical grid spacing in the TTL and (iii) with a $60 \mathrm{~km}$ horizontal grid spacing and a $850 \mathrm{~m}$ vertical grid spacing in the TTL.

Since it is not possible to compare the idealised tracers with measurements, we used an indirect evaluation of the tracer transport through the assessment with meteorological fields from local aircraft data and statistical comparisons. The detailed comparison with coordinated flights of the Geophysica and Falcon aircraft performed during the SCOUTDarwin campaign shows that the three simulations provide a generally good agreement with the measurements for temperature, horizontal wind speed/direction and specific humidity. However, the high resolution (HR) simulation is better correlated to the data and provides an enhancement of the variability. This result is consistent with the statistical comparison of the simulation results with the series of radiosoundings launched from Manus Island during the simulation period. The comparison with the TRMM surface rainrate estimates shows that the three simulations reproduce well rainrates in areas of deep convection. The HR run simulates better both deep convection and light precipitation compared to REF and CVR. It also provides a better forecast of the occurrence and intensity of convection. Degrading the 
horizontal or vertical resolutions leads to an underestimation of the occurrence and of the intensity of convection.

The impact of both horizontal and vertical resolutions is large on the transport of tropospheric tracers within the TTL. Due to the larger upward velocities in the TTL in HR compared to CVR, the HR simulation provides significantly larger tracer amounts of tracers and fluxes in the TTL. Refining the vertical resolution in the TTL from $850 \mathrm{~m}$ to $300 \mathrm{~m}$ allows convection to reach higher altitudes in the upper troposphere and provides larger vertical fluxes leading to a large increase of the tracer transport into the TTL. The use of a fine horizontal resolution together with a fine vertical resolution provides more frequent convective events with enhanced vertical velocities giving much more tracer transport into the TTL. Contrarily to REF and CVR, HR predicts occasional overshooting above the dynamical barrier at the cold point level. There are only small differences between the three simulations for stratospheric tracers on average. However, HR provides larger mixing ratios below $16.9 \mathrm{~km}$ altitude than REF. This also indicates significant irreversible transport in the TTL by overshooting convection in the HR simulation.

The present study was restricted to the Maritime continent and an extension to other tropical convection areas and periods is planned: West Africa in summer 2006 using AMMA (African Monsoon Multidisciplinary Analyses) data and South America for February and March 2005 using TROCCINOX (TROpical Convection, CIrrus and Nitrogen OXides experiment) data. This study will be the scope of a forthcoming paper.

To go a step further, real tracers could be used to make a direct evaluation of the tracer transport. This can only be achieved if the tracer emissions are properly determined. One possibility would be to use the detailed emission inventories over West Africa from the AMMA project.

Acknowledgements. This work was supported by the European integrated project SCOUT-O3 (GOCE-CT-2004-505390) and by the program LEFE/INSU in France (projects UTLS-tropicale and Tropopause 2009). This work was granted access to the HPC resources of CINES under the allocation 2008- c2008012536 made by GENCI (Grand Equipement National de Calcul Intensif). The TRMM data were provided by GSFC/DAAC, NASA. The Falcon meteorological data were provided by the DRL (Deutsches Zentrum für Luft- und Raumfahrt, Germany) and the Geophysica meteorological data by the CAO (Central Aerological Observatory, Russia) and MDB (Myasishchev Design Bureau, Russia). We acknowledge A. Protat and P. May from the BMRC (Bureau of Meteorology Research Center). CATT-BRAMS is a free software provided by CPTEC/INPE and distributed under the CC-GNU GPL license.

Edited by: N. Harris

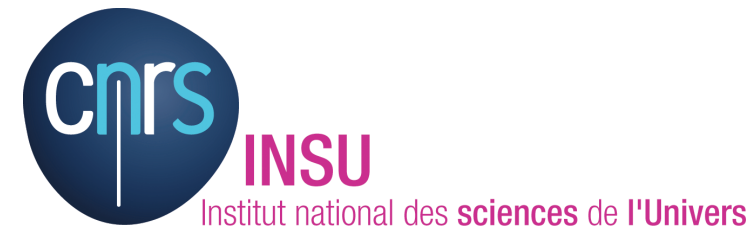

The publication of this article is financed by CNRS-INSU.

\section{References}

Aghedo, A., Rast, S., and Schultz, M. G.: Sensitivity of tracer transport to model resolution, forcing data and tracer lifetime in the general circulation model ECHAM5, Atmos. Chem. Phys. Discuss., 8, 137-160, 2008,

http://www.atmos-chem-phys-discuss.net/8/137/2008/.

Arakawa, A. and Schubert, W. H.: Interaction of a cumulus cloud ensemble with the large-scale environment, Part I. J. Atmos. Sci., 31, 674-701, 1974.

Brankovic, C. and Gregory, D.: Impact of horizontal resolution on seasonal integrations, Clim. Dyn., 18, 123-143, 2001.

Brunner, D., Staehelin, J., Rogers, H. L., Köhler, M. O., Pyle, J. A., Hauglustaine, D. A., Jourdain, L., Berntsen, T. K., Gauss, M., Isaksen, I. S. A., Maijer, E., Van Velthoven, P., Pitari, G., Mancini, E., Grewe, V., and Sausen, R.: An evaluation of the performance of chemistry transport models - Part 2: Detailed comparison with two selected campaigns, Atmos. Chem. Phys., 5, 107-129, 2005, http://www.atmos-chem-phys.net/5/107/2005/.

Brunner, D., Siegmund, P., May, P. T., Chappel, L., Schiller, C. Müller, R., Peter, T., Fueglistaler, S., MacKenzie, A. R., Fix, A., Schlager, H., Allen, G., Fjaeraa, A. M., Streibel, M., and Harris, N. R. P.: The SCOUT-O3 Darwin aircraft campaign: rationale and meteorology, Atmos. Chem. Phys., 9, 93-117, 2009, http://www.atmos-chem-phys.net/9/93/2009/.

Corti, T., Luo, B. P., de Reus, M., Brunner, D., Cairo, F., Mahoney, M. J., Martucci, G., Matthey, R., Mitev, V., dos Santos, F. H., Schiller, C., Shur, G., Sitnikov, N. M., Spelten, N., Vossing, H. J., Borrmann, S., and Peter, T.: Unprecedented evidence for overshooting convection hydrating the tropical stratosphere, Geophys. Res. Lett., 35, L10810, doi:10.1029/2008GL033641, 2008.

Deng, A., Seaman, N. L., Hunter, G. K., and Satuffer, D. R.: Evaluation of interregional transport using the MM5-SCIPUFF system, J. Appl. Meteorol. 43, 1864-1886, 2004.

Fueglistaler, S., Dessler, A., Dunkerton, T. J., Folkins, I., Fu, Q., and Mote, P. W.: The tropical tropopause layer, Rev. Geophys., 47, RG1004, doi:10.1029/2008RG000267, 2009.

Freitas, S. R., Longo K. M., Silva Dias, M. A. F., Chatfield, R., Silva Dias, P., Artaxo, P., Andreae, M. O., Grell, G., Rodrigues, L. F., Fazenda, A., and Panetta, J.: The Coupled Aerosol and Tracer Transport model to the Brazilian developments of the Regional Atmospheric Modeling System (CATT-BRAMS). Part 1: model description and evaluation, Atmos. Chem. Phys., 9, 2843-2861, 2009, http://www.atmos-chem-phys.net/9/2843/2009/.

Gevaerd, R. and Freitas, S. Estimativa operacional da umidade do solo para iniciao de modelos de previso numrica da atmosfera. Parte 1: descrio da metodologia e validao, Brazilian Journal of Meteorology, LBA Special Issue, 21, 1-15, 2006. 
Gray, S. L.: A case study of stratosphere to troposphere transport: the role of convective transport and the sensitivity to model resolution, J. Geophys. Res., 108(D18), 4590, doi:10.1029/2002JD003317, 2003.

Grell, G. A.: Prognostic evaluation of assumptions used by cumulus parameterizations, Mon. Wea. Rev., 121, 764-787, 1993.

Grell, G. A. and Dévényi, D.: A generalized approach to parameterizing convection combining ensemble and data assimilation, Geophys. Res. Lett., 29, 1693, doi:10.1029/2002GL015311, 2002.

Harrington, J. Y.: The effects of radiative and microphysical processes on simulated warm and transition season Arctic stratus, PhD Diss., Atmospheric Science Paper N 637, Colorado State University, Department of Atmospheric Science, Fort Collins, CO 80523, USA, 289 pp., 1997.

Huffman, G. J., Adler, R. F., Bolvin, D. T., Gu, G., Nelkin, E. J., Bowman, K. P., Hong, Y., Stocker, E. F., and Wolff, D. B.: The TRMM multi-satellite precipitation analysis: quasi-global, multi-year, combined-sensor precipitation estimates at fine scale, J. Hydrometeor, 8(1), 38-55, 2007.

Kain, J. S. and Fritsch, J. M.: A one-dimensional entraining/detraining plume model and its application in convective parameterization. J. Atmos. Sci., 47, 2784-2802, 1990.

Lane, T. P. and Knievel, J. C.: Some effects of model resolution on simulated gravity waves generated by deep mesoscale convection, J. Atmos. Sci., 62, 3408-3419, 2005.

Marécal, V., Rivière, E. D., Held, G., Cautenet, S., and Freitas, S.: Modelling study of the impact of deep convection on the UTLS air composition. Part I: analysis of ozone precursors. Atmos. Chem. Phys., 6, 1567-1584, 2006, http://www.atmos-chem-phys.net/6/1567/2006/.

Pope, V. D., Pamment, J. A., Jackson, D. R., and Slingo, A., The representation of water vapour and its dependence on vertical resolution in the Hadley Centre climate model, J. Clim., 14, 3065-3085, 2001.

Phillips, T. J., Corsetti, L. C., and Grotch, S. L.: The impact of horizontal resolution on moist processes in the ECMWF model, Clim. Dynam., 11, 85-102, 1995.

Pickering, K. E., Thompson, A. M., Wang, Y., Tao, W.-K., McNamara, D. P., Kirchhoff, V. W. J. H., Heikes, B. G., Sachse, G. W., Bradshaw, J. D., Gregory, G. L., and Blake, D. R.: Convective transport of biomass burning emissions over Brazil during TRACE A, J. Geophys. Res., 101(D19), 23993-24012, 1996.
Rind, D., Lerner, J., Jonas, J., and McLinden, C.: Effects of resolution and model physics on tracer transports in the NASA Goddard Institute for Space Studies general circulation models, J. Geophys. Res., 112, D09315, doi:10.1029/2006JD007476, 2007.

Roeckner, E., Brokopf, R., Esch, M. Giorgetta, M., Hagemann, S., and Kornblueh, L.: Sensitivity of simulated climate to horizontal and vertical resolution in the ECHAM5 atmosphere model, J. Clim., 19, 3771-3791, 2006.

Smith, S. A., Doyle, J. D., Brown, A. R., and Webster, S., Sensitivity of resolved mountain drag to model resolution for MAP case-studies, Q. J. Roy. Meteor. Soc., 132, 1467-1487, 2007.

Sperber, K. R., Hameed, S., Potter, G. L., and Boyle, J. S.: Simulation of the northern summer monsoon in the ECMWF model: Sensitivity to horizontal resolution, Mon. Weather Rev., 122, 2461-2481, 1994.

Tiedke, M.: A comprehensive mass flux scheme for cumulus parameterization in large scale models, Mon. Weather Rev., 117, 1779-1800, 1989.

Vaughan, G., Schiller, C., MacKenzie, A. R., Bower, K., Peter, T., Schlager, H., Harris, N. R. P., and May, P. T., SCOUTO3/ACTIVE high altitude aircraft measurements around deep tropical convection, B. Am. Meteor. Soc., 89, 647-661, 2008.

Walko, R. L., Cotton, W. R., Meyers, M. P., and Harrington, J. Y.: New RAMS cloud microphysics parameterization. Part I: the single-moment scheme, 38, 29-62, 1995.

Wang, Y., Tao, W.-K., Pickering, K. E., Thompson, A. M., Kain, J. S., Adler, R. F., Simpson, J., Keehn, P. R., and Lai, G. S.: Mesoscale model simulations of TRACE A and Preliminary Regional Experiment for Storm-scale Operational and Research Meteorology convective systems and associated tracer transport, J. Geophys. Res., 101(D19), 24013-24027, 1996.

Wild, O. and Prather, M. J.: Global tropospheric ozone modelling: quantifying errors due to grid resolution, J. Geophys. Res., 111, D11305, doi:10.1029/2005JD0006605, 2006.

Zhang, G. J. and McFarlane, N. A.: Sensitivity of climate simulations to the parameterization of cumulus convection in the Canadian Climate Centre General Circulation Model, Atmos. Ocean., 33, 407-446, 1995. 